\title{
AVALIAÇÃO EPIDEMIOLÓGICA DE TRAUMATISMO DENTÁRIO ASSOCIADA AO OVERJET E SELAMENTO LABIAL EM ESCOLARES DO MUNICÍPIO DE PIRACICABA-SP-BRASIL.
}

\section{Fernanda Moreno de Oliveira*, Ana Carolina Correia Laurindo de Cerqueira Neto, Brenda Paula Figueiredo de Almeida Gomes, José Flávio Affonso de Almeida, Alexandre Augusto Zaia, Dagmar de Paula Queluz, Marina Angélica Marciano da Silva, Adriana de Jesus Soares.}

\section{Resumo}

O trauma dental é um problema de saúde pública devido a sua alta prevalência, afetando aproximadamente 10-35\% da população, sendo uma das principais causas de emergência odontológica em crianças e adolescentes. Durante a XXIV Jornada Odontológica de Piracicaba, realizada pela FOP-UNICAMP, o presente estudo foi realizado a fim de investigar a associação entre a ocorrência de traumatismos dentários e de fatores de risco como overjet acentuado $(>3 \mathrm{~mm})$ e proteção labial inadequada.

\section{Palavras-chave:}

epidemiologia, fatores de risco, traumatismos dentários.

\section{Introdução}

O trauma dental é uma patologia frequente em crianças em idade escolar. Os dentes incisivos superiores são os mais atingidos devido a sua posição mais anterior e proeminente no arco. Além disso, a presença de fatores de risco aumenta a incidência nessa região. Diversos autores (Cortes et al, 2001; Soriano et al, 2007) afirmam a relação entre sobressaliência aumentada e trauma. Segundo Nguye (1999), pacientes com overjet $>3 \mathrm{~mm}$ tem duas vezes mais chance de sofrer traumatismo. A postura labial por si só não é considerada um fator predisponente, no entanto apresenta colinearidade com a presença de overjet acentuado.

O presente estudo tem como objetivo avaliar a presença de traumatismo em dentes permanentes de escolares advindos de escolas públicas que apresentam faixa etária de 7 a 10 anos. Além de analisar a ocorrência destas lesões traumáticas com fatores de risco (overjet acentuado e selamento labial incompleto).

\section{Resultados e Discussão}

A coleta dos dados ocorreu na XXIV Jornada Odontológica de Piracicaba $O$ exame foi realizado sob iluminação natural, com auxílio de espátulas de madeira e espelhos clínicos estéreis para analisar a presença de trauma, e as sequelas resultantes deste traumatismo. Para a avaliação do overjet foi orientado que a criança permanecesse na posição de máxima intercuspidação e com um grafite era marcado a distância da face vestibular do incisivo inferior à face incisal do incisivo superior em uma espátula. Para avaliação do selamento labial a criança leu um texto mentalmente, sem mover os lábios, e cabia ao examinador avaliar se a postura labial era adequada (posição de repouso) ou inadequada. A amostra sofreu redução devido ao número de crianças que ainda apresentavam dentição decídua.

Tabela 1. Frequência de overjet incisal $\leq 3 \mathrm{~mm}$ e $>3 \mathrm{~mm}$

\begin{tabular}{lll}
\hline Overjet & $\leq 3 \mathrm{~mm}$ & $>3 \mathrm{~mm}$ \\
\hline Frequência & $47,1 \%(418)$ & $33,0 \%(294)$ \\
\hline
\end{tabular}

Tabela 2. Frequência da presença de selamento labial adequado e inadequado.

\begin{tabular}{lll}
\hline Selamento Labial & Adequado & Inadequado \\
\hline Frequência & $83,1 \%(739)$ & $16,9 \%(150)$ \\
\hline
\end{tabular}

Tabela 3. Análise de regressão simples e múltipla para a associação entre a presença de trauma dental com sexo, idade, overjet e selamento labial.

\begin{tabular}{|c|c|c|c|c|c|c|}
\hline \multirow[b]{3}{*}{ Variável } & \multirow[b]{3}{*}{ Categoria } & \multicolumn{2}{|c|}{ Presença de trauma dental } & \multicolumn{3}{|c|}{ Análise simples } \\
\hline & & \multirow{2}{*}{$\frac{\operatorname{sim}}{\mathrm{n}(\%)}$} & \multirow{2}{*}{$\begin{array}{c}\text { Não } \\
\mathrm{n}(\%)\end{array}$} & \multirow[b]{2}{*}{ OR bruto } & \multirow[b]{2}{*}{ IC $(95 \%)$} & \multirow[b]{2}{*}{ p-valor } \\
\hline & & & & & & \\
\hline \multirow{2}{*}{ Sexo } & Masculino & $54(12,74)$ & $370(87,26)$ & 2,07 & $1,27-3,38$ & 0,0044 \\
\hline & Feminino & $26(6,58)$ & $369(93,42)$ & ref & & \\
\hline \multirow{2}{*}{ Idade } & $\leq 8$ anos & $39(8,78)$ & $405(91,22)$ & ref & & \\
\hline & $>8$ anos & $40(11,17)$ & $318(88,38)$ & 1,31 & $0,82-2,08$ & 0,3127 \\
\hline \multirow{2}{*}{ Overjet } & $\leq 3 \mathrm{~mm}$ & $33(8,35)$ & $362(91,65)$ & ref & & \\
\hline & $>3 \mathrm{~mm}$ & $36(12,90)$ & $243(87,10)$ & 1,62 & $0,99-2,68$ & 0,0725 \\
\hline Selamento & Adequado & $55(9,14)$ & $547(90,86)$ & ref & & \\
\hline labial & Inadequado & $19(13,19)$ & $125(86,81)$ & 1,52 & $0,87-2,64$ & 0,1908 \\
\hline
\end{tabular}

\section{Conclusões}

A ocorrência de traumatismos dentários é 2,07 vezes maior no sexo masculino com relação ao feminino. Além disso, a prevalência de traumatismos reforça a necessidade de campanhas de prevenção nas escolas acerca desse assunto.

${ }^{1}$ Cortes, M.I.S.; Marcenes, W; Sheiham, A. Community Dent. Oral Epdemiol. 2002, 30, 193-8.

${ }^{2}$ Nguyen, Q.V.; Bezemer, P.D.; Habets, L.; Prahl-Andreasen, B. Eur J Orthod, 1999, 21, 503-15.

${ }^{3}$ Soriano, E.R.; Caldas Jr, A.F.; Goes, P.S.; Dental Traumatol, 2004, 20, 246 50 . 